\title{
DUKUNGAN DOSEN-DOSEN UMN UNTUK KEGIATAN TNI MASUK DESA- MELATIH MEMBATIK GAYA KHAS TANGERANG
}

\author{
Yohanes Langgar Billy MM \\ MV Santi Hendrawati \\ Dr Indiwan Seto Wahjuwibowo MSI \\ Dosen Ilmu Komunikasi Universiitas Multimedia Nusantara \\ E-Mail: indiwan@umn.ac.id
}

\begin{abstract}
ABSTRAK
Kegiatan TNI Masuk desa, yang sekarang berubah nama menjadi TNI Manunggal Membangun Desa merupakan ajang kegiatan tahunan yang diselenggarakan di sejumlah wilayah yang memang membutuhkan sebagaimana dilakukan oleh jajaran Kodim 0510 Tigaraksa Kabupaten Tangerang, yang berlokasi di sejumlah desa dan sekolah di wilayah Kabuooaten Tangerang Banten.

SMK Mutiara Bangsa, Kecamatan Kemiri, Kabupaten Tangerang berkesempatan dikunjungi satuan tugas (Satgas) Non Fisik TNI Manunggal Membangun Desa (TMMD) 105 Kronjo, Kodim 0510/Tigaraksa, Selasa (30/7).Selain mendapatkan penyampaian materi soal bela negara, bahaya penyalahgunaan narkoba, kesehatan reproduksi remaja dan tertib berlalu lintas, pelajar juga mendapatkan pelatihan membatik.Batik dipilih satgas disosialisasikan kepada kaum milenial, karena merupakan warisan budaya bangsa yang telah mendunia. Selain itu pelatihan membatik dilaksanakan juga di desa Bluk Buk Kronjo bagi warga desa dan sejumlah istri tentara di lingkungan Kodim 0510 Tigaraksa Kabupaten Tangerang. Pelatihan dilakukann oleh dosen-dosen UMN menggunnakan teknik praktik langsung.

Metode yang dilakukan, pertama-tama mencari tahu dan mengidentifikasi masalah dan kebutuhan mitra dalam hal ini adalah yang merasa kesulitan dalam membuat produk khas daerahh yang bisa dijual, lalu memberi pelatihan dan pendampingan peserta dalam membuat batik dan emberi pelatihan dan pendampingan agar SDM Mitra bisa memasarkan hasil produk batik mereka ke media social Kesimpulan yang bisa diambil dari kegiatan pengabdian kepada masyarakat ini yang dilakukan oleh Yohanes Langgar Billy, Indiwan seto dan MV Santi hendrawati dosen-dosen UMN adalah pada dasarnya warga binaan, termasuk di dalamnya generasi muda di kawasan Kemiri Kabuatan Tangerang sebenarnya memiliki minat serta antusias yang besar untuk membatik. Selain itu, corak khas daerah Tangerang sangat memungkinkan dimunculkannya motif batik yang khas. Yang kedua, teknik membatik menggunakan teknik canting memang membutuhkan praktik dan pembiasaan praktik yang lama sehingga disarankan agar proses pelatihan membatik ini terus ditingkatkan oleh peserta di rumah masing-masing, agar pemakaian canting dan teknik pewarnaan batik bisa dikuasai.
\end{abstract}

Keywords: TMMD 2019, pelatihan membatik, teknik batik canting, dosen UMN

Ekonomi, Sosial, dan Budaya 1515 


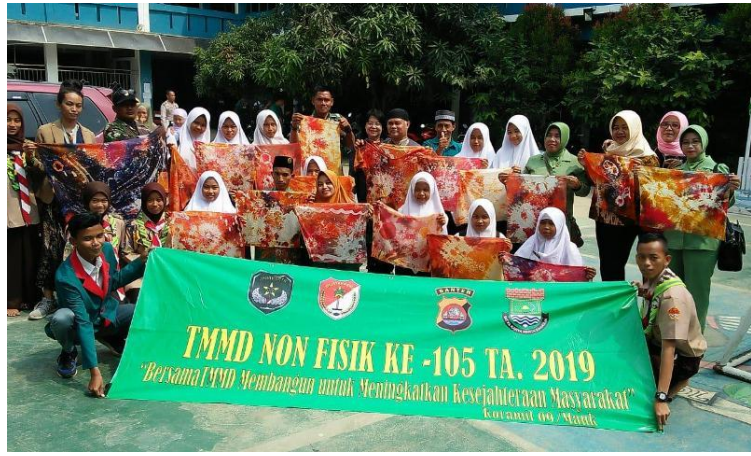

PENDAHULUAN

Pemerintah Kabupaten Tangerang dan TNI bersinergi menyelenggarakan TNI Manunggal Membangun Desa (TMMD) ke105. Lokasinya di lapangan bola kandangan gede kampung bakungan kecamatan kronjo. TMMD kali ini menyasar pembangunan jalan Desa Blukbuk, Kecamatan Kronjo, Kabupaten Tangerang sepanjang 1.130 meter dan lebar 4 meter."Ini merupakan jalan vital yang menghubungakan empat desa," ujar Komandan Kodim 0510/Tigaraksa, Letkol Inf Parada Warta Nusantara Tampubolon, Kamis (10/7/2019. Dalam kegiatannya ini TNI bersinergi juga dengan sejumlah kampus, khususnya Universitas Multimedia Nusantara yang kebagian memberikan sejumlah pelatihan, diantaranya adalah pelatihan membatik bagi warga masyarakat desa Blukbuk, Keronjo. Kabupaten Tangerang.

Kegiatan TMMD yang dilakukan TNI AD bertujuan untuk membantu Pemda Kabupaten Tangerang dalam mempercepat pembangunan di daerah khususnya di pedesaan. Sementara untuk sasaran nonfisik, seperti penyuluhan kesehatan.
Selain itu TMMD ke-105 bekerja sama dengan Mahasiswa dari sejumlah kampus, diantaranya UMN untuk membangun generasi penerus melalui TMMD non-fisik. Bentuknya berupa penyuluhan terhadap para pemuda dan masyarakat tentang wawasan kebangsaan yang di wilayah Koramil jajaran Kodim 0510/Tigaraksa. Acara ini diramaikan dengan penyuluhan mengenai bahaya narkoba, kerukunan umat beragama serta menangkal paham radikalisme, public speaking, dan pelatihan membatik.

SMK Mutiara Bangsa, Kecamatan Kemiri, Kabupaten Tangerang berkesempatan dikunjungi satuan tugas (Satgas) Non Fisik TNI Manunggal Membangun Desa (TMMD) 105 Kronjo, Kodim 0510/Tigaraksa, Selasa (30/7).Selain mendapatkan penyampaian materi soal bela negara, bahaya penyalahgunaan narkoba, kesehatan reproduksi remaja dan tertib berlalu lintas, pelajar juga mendapatkan pelatihan membatik.Batik dipilih satgas disosialisasikan kepada kaum milenial, karena merupakan warisan budaya bangsa yang telah mendunia. Sehingga sebagai salah satu kebanggaan bangsa, keterampilan membatik harus dikuasai remaja.

Pelajar sekolah tersebut mencoba menghasilkan karya batik hasil tangannya sendiri. Di bawah bimbingan seorang mentor, mereka asyik berekspresi dari Ekonomi, Sosial, dan Budaya 1515 
membuat pola sampai menyelupkan kain ukuran sekitar setengah meter ke cairan malam.Hasilnya, beragam hasil karya mereka pun nampak. Meski masih sangat amatiran, namun pengalaman perdana mereka membatik itu sangat berkesan. "Ternyata enggak mudah membatik itu, perlu kesabaran dan keuletan. Tapi mengasyikan," kata Anita, siswa SMK Mutiara Bangsa.Anita mengaku, pengalaman membatik itu pertama kalinya ia terima. Sebelumnya, ia hanya menjadi konsumen semata. "Suka sih sama batik, saya punya beberapa koleksi batik. Kadang dipakai untuk acara khusus," tambahnya.Sebelumnya, Dansatgas TMMD 105 Kronjo Letkol Inf Parada Warta Nusantara Tampubolon mengatakan, Pelatihan membatik tersebut sangat penting. Sebab, kata Parada, batik adalah warisan budaya yang harus dilestarikan.

Masalah yang dihadapi mitra ? Dalam hal ini mitra sasaran kegiatan TNI Manunggal membangun desa yakni siswa SMK di Kecamatan Kemiri dan warga desa Blukbuk Kronjo Kabupaten Tangerang

\begin{tabular}{|l|l|l|}
\hline MASALAH & $\begin{array}{l}\text { URAIAN } \\
\text { MASALAH }\end{array}$ & $\begin{array}{l}\text { SOLUSI YANG } \\
\text { DITAWARKA } \\
\mathrm{N}\end{array}$ \\
\hline Banyak & Banyak & Memberi \\
sumber daya & penggangur & pelatihan dan \\
yang kurang & an yang & pendampinga \\
termanfaatkan & tidak & $\mathrm{n}$ \\
\hline
\end{tabular}

\begin{tabular}{|c|c|c|}
\hline & $\begin{array}{l}\text { mengerti } \\
\text { harus } \\
\text { mengerjaka } \\
\mathrm{n} \text { apa }\end{array}$ & $\begin{array}{l}\text { pesertadalam } \\
\text { membuat } \\
\text { batik }\end{array}$ \\
\hline $\begin{array}{l}\text { Banyak siswa } \\
\text { yang tidak } \\
\text { mengetahui } \\
\text { nilai batik }\end{array}$ & $\begin{array}{l}\text { Siswa SMK } \\
\text { banyak } \\
\text { yang sudah } \\
\text { mengikuti } \\
\text { pelatihan } \\
\text { batik tetapi } \\
\text { tidak tahu } \\
\text { bagaimana } \\
\text { membuat } \\
\text { batik yang } \\
\text { mampu } \\
\text { dijual }\end{array}$ & $\begin{array}{l}\text { Memberi } \\
\text { pelatihan dan } \\
\text { pendampinga } \\
\mathrm{n} \text { agar mitra } \\
\text { bisa } \\
\text { menguasai } \\
\text { kemampuan } \\
\text { membatik } \\
\text { dan } \\
\text { mengetahui } \\
\text { bagaimana } \\
\text { cara } \\
\text { memasarkan } \\
\text { nya. }\end{array}$ \\
\hline $\begin{array}{l}\text { Banyak alat } \\
\text { yang tersedia } \\
\text { terkait dengan } \\
\text { kerajinan batik } \\
\text { tidak tahu } \\
\text { memanfaatka } \\
\text { nnya }\end{array}$ & $\begin{array}{l}\text { Mereka } \\
\text { memiliki } \\
\text { peralatan } \\
\text { tetapi tidak } \\
\text { bisa } \\
\text { memanfaat } \\
\text { kan secara } \\
\text { maksimal } \\
\text { untuk } \\
\text { membatik }\end{array}$ & $\begin{array}{l}\text { Memberi } \\
\text { pelatihan } \\
\text { praktis } \\
\text { membuat } \\
\text { batik dengan } \\
\text { menggunaka } \\
\text { n peralatan } \\
\text { yang tersedia }\end{array}$ \\
\hline $\begin{array}{l}\text { Memiliki } \\
\text { handphone } \\
\text { dan serring } \\
\text { merekam } \\
\text { kegiatan } \\
\text { menggunakan } \\
\text { kamera video } \\
\text { tapi tidak } \\
\text { mengetahui } \\
\text { bagaimana } \\
\text { caranya } \\
\text { memasarkan } \\
\text { batik }\end{array}$ & $\begin{array}{l}\text { Aplikasi } \\
\text { yang } \\
\text { digunakan } \\
\text { di } \\
\text { handphone } \\
\text { banyak } \\
\text { yang terkait } \\
\text { dengan } \\
\text { perekaman } \\
\text { video, tapi } \\
\text { tidak bisa } \\
\text { dimanfaatk } \\
\text { an secara } \\
\text { efektif }\end{array}$ & $\begin{array}{l}\text { Menjelaskan } \\
\text { dan } \\
\text { membimbing } \\
\text { peserta } \\
\text { memanfaatk } \\
\text { an aplikasi } \\
\text { membuat } \\
\text { video praktis } \\
\text { untuk } \\
\text { memasarkan } \\
\text { produk batik } \\
\text { yang } \\
\text { dihasilkan }\end{array}$ \\
\hline
\end{tabular}

Ekonomi, Sosial, dan Budaya 1516 
Berdasarkan masalah dan solusi yang ditawarkan maka pengabdi memberikan pelatihan dan pendampingan bagaimana membuat batik, mewarnai dan membuat produk batik yang sesuai dengan selera pasar dan disesuaikan dengan ciri khas Tangerang

\section{B. Tinjauan Pustaka/Kerangka berpikir}

Dalam pelatihan batik yang dilakukan oleh dosen-dosen UMN di sejumlah lokasi daerah binaan acara kegiatan TNI Manunggal Membangun Desa menggunakan sejumlah teknik membatik yaitu teknik Canting dan teknik ikat serta kreasi baru. Ada beberapa teknik batik salah satunya adalah teknik canting. Canting adalah alat khas Jawa yang digunakan untuk menuliskan motif batik diatas seulas kain mori. Canting berfungsi sebagai pena dengan cairan malam sebagai tintanya. Seluruh proses pembatikan dengan teknik canting tulis dilakukan secara tradisional dan manual, karenanya motif satu dengan yang lain tidak simetris dan ukurannya pun tidak akan bisa sama persis.

Pada penggunaan teknik canting tulis, warna motif pada kain bagian depan dan belakang memiliki kesamaan, hal ini disebabkan proses membatik dilakukan di kedua sisi kain. Batik canting tulis juga memiliki aroma yang khas. Hal ini dikarenakan pada teknik canting tulis proses pewarnaan menggunakan pewarna alami, misalnya kulit kayu teger untuk warna kuning, daun tom dan akarnya untuk warna biru, kulit kayu tingi untuk warna hitam, dan kayu jambal untuk warna cokelat. Ukuran kain yang digunakannyapun tergolong besar, biasanya sekitar $2 \times 1,25$ meter. Khusus batik-batik kuno
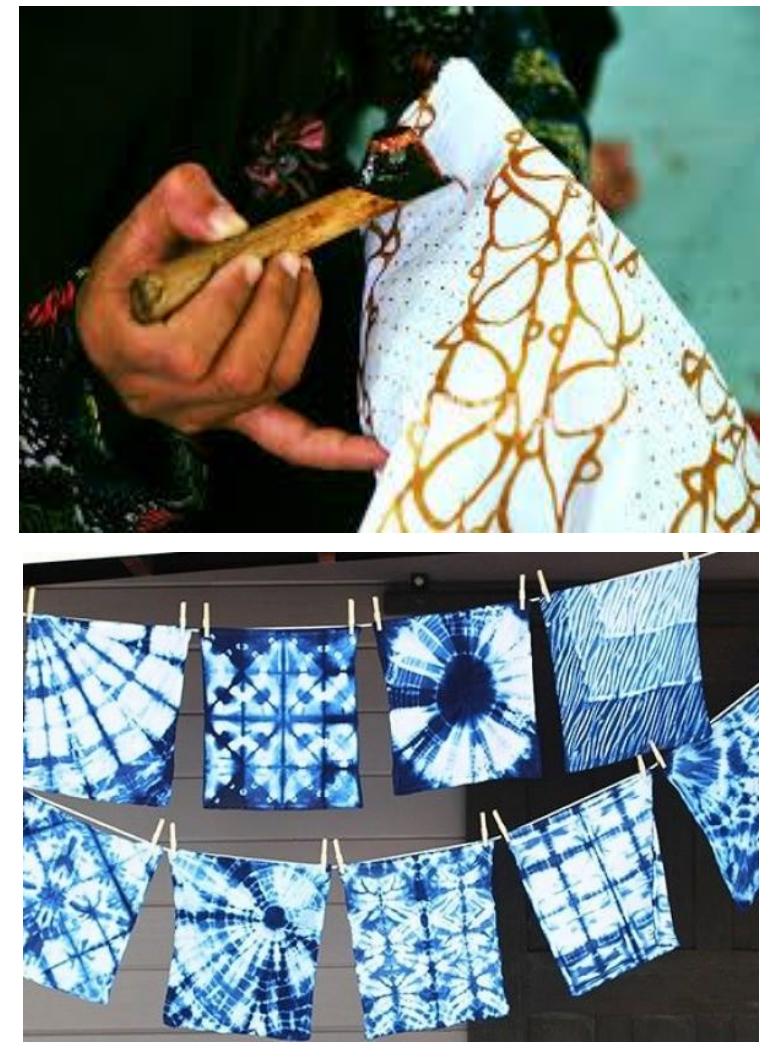

biasanya terdapat inisial nama pembatik biasanya terdapat di ujung kain. Karena kerumitannya, teknik ini membutuhkan jiwa seniman dan ketelitian yang tinggi serta memakan waktu yang lama. Hal itulah yang menyebabkan harga batik tulis ini kemudian menjadi sangat mahal.

Sedangkan teknik berikutnya ,Teknik celup ikat sangatlah mudah. Pembuatan motif pada kain dibuat dengan cara mengikat sebagian kain lalu mencelupkannya kedalam cairan pewarna. Dalam tenik celup ikat, kain terkadang dicelupkan ke beberapa warna untuk mendapatkan warna yang bervariasi, sementara corak motif yang didapatkan tergantung pada kreasi ikatan-ikatan yang dibuat. Teknik celup ikat juga dikenal dengan nama jumputan, tritik, sasirangan dan pelangi.

C. METODOLOGI

Ekonomi, Sosial, dan Budaya 1517 
Dalam kegiatan pengabdian ini metode yang digunakan adalah sebagai berikut:

1. Pertama-tama mencari tahu dan mengidentifikasi masalah dan kebutuhan mitra dalam hal ini adalah yang merasa kesulitan dalam membuat produk khas daerahh yang bisa dijual

2. Memberi pelatihan dan pendampingan peserta dalam membuat batik

3. Memberi pelatihan dan pendampingan agar SDM Mitra bisa memasarkan hasil produk batik mereka ke media sosial

\section{D.PELAKSANAAN KEGIATAN DAN PEMBAHASAN}

Saat pelaksanaan kegiatan membatik, pertama-tama tim dosen UMN yang terdiri dari empat orang dibantu seorang narasumber batik professional menjelaskan apa pentingnya membatik, teknik dasar membatik yang bisa dilakukan oleh siapa saja. Kemudian ditambah dengan penjelasan peralatan-peralatan yang digunakan saat membatik dilakukan.

Narasumber menjelaskan bahwa ada dua proses besar yang dilakukan yaitu membatik kemudian mewarnai batik sesuai dengan target yang diinginkan.

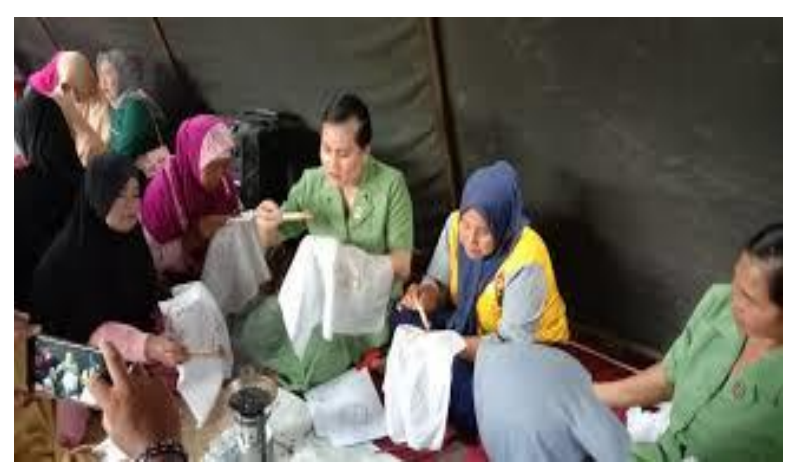

Keterangan Gambar: Ibu-ibu persit Kodim 0510 Tangerang, bersama warga desa Bluk-bluk belajar batik

Kemudian, setelah diajarkan secara teori mengenai apa saja yang akan dilakukan saat membatik, para peserta diminta membuat skets gambar motif batik yang disesuaikan dengan gaya dan desain setempat, baru kemudian peserta membatik menggunakan canting.

Hasil dari sket di kertas tersebut kemudian dipindahkan ke kain katun atau mori yang disediakan kemuidian dipertegas menggunakan canting, dan setelah selesai kemudian diwarnai. Pelaksanaan kegiatan membatik di lakukan pada tanggal

$$
\text { Begitu juga saat memberi pelatihan }
$$

batik di desa Kemiri kecamatan Kemiri Kabupaten Tangerang, Kegiatan diawali dgn Pemberian teori membatik yg di lanjutkan praktek yaitu : Mendesain motif batik di atas kertas menggunakan pensil ukuran sesungguhnya, Menebalkan sket dengan spidol hitam, Memindahkan sket desain di atas kain $100 \%$ serat alami dengan menggunakan pensil $4 \mathrm{~B}$ atau 6B, Memulai kegiatan mencanting dengan menorehkan malam/wax yang sudah dicairkan di wajan batik, 


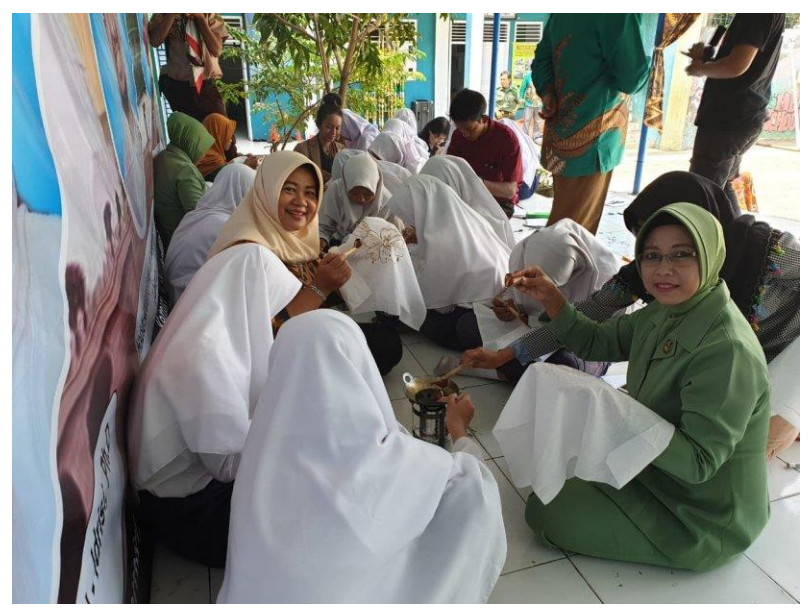

Kain direndam di air biar untuk membuka pori2 kain di tiriskan tidak boleh diperas dijemur ditempat teduh selama 15 menit, Kain siap diwarnai di bahan tahap 1 yaitu pewarna naphtol (kode ASG khusus ke kuning, AS, ASD, AS-OL, ASBS, AS-BO) kain ditiriskan tidak boleh diperas dijemur $1 / 2$ jam, Kain diwarnai ke tahap ke 2 dengan pewarna garam (dengan kode warna Kuning GC, Orange, Merah R, Merah B, Merah N, Biru B, Hitam) kain ditiriskan tidak boleh diperas dijemur $1 / 2$ jam, Kain dinetral air untuk menghilangkan sisa warna yang masih menempel dikain, Kain di GEBYOK/pelorotan malam (menghilangkan malam yang menempel di kain dengan cara direndam di air mendidih di bekas kaleng bekas cat $25 \mathrm{~kg}$ air $3 / 4$.

Dari sejumlah praktik membatik yang dilakukan oleh warga/mitra yang dipandu oleh dosen-dosen UMN kemudian dikirimkan ke media social sebagai bagian penting dari proses marketing komunikasi. Sejumlah hasilnya dikirimkan ke Instagram dan facebook serta diupload ke Youtube .

\section{KESIMPULAN DAN SARAN}

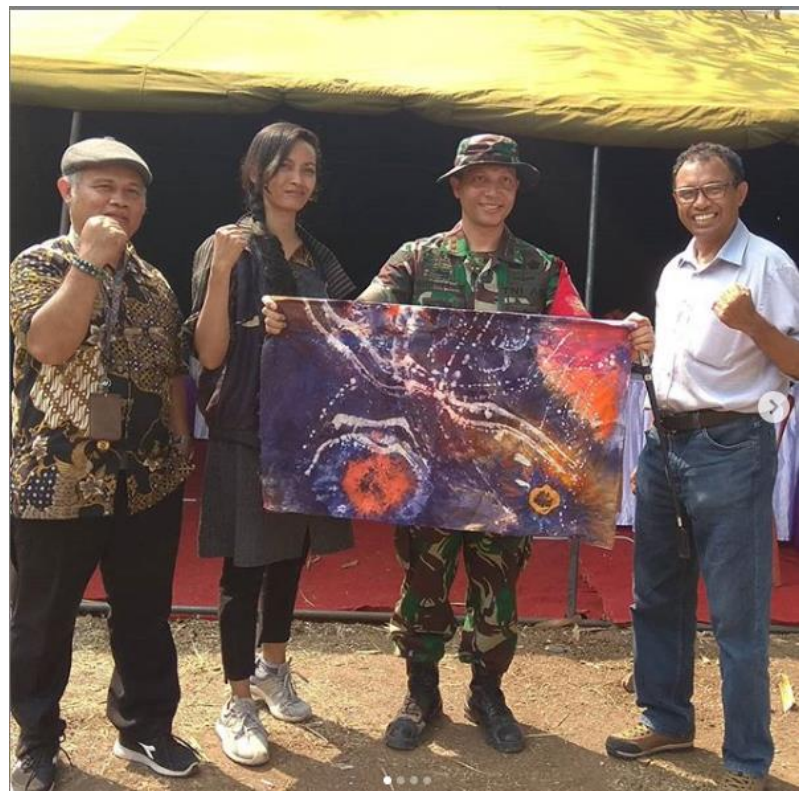

Kesimpulan yang bisa diambil dari kegiatan pengabdian kepada masyarakat ini yang dilakukan oleh Yohanes Langgar Billy, Indiwan seto dan MV Santi hendrawati dosendosen UMN adalah pada dasarnya warga binaan, termasuk di dalamnya generasi muda di kawasan Kemiri Kabuatan Tangerang sebenarnya memiliki minat serta antusias yang besar untuk membatik. Selain itu, corak khas daerah Tangerang sangat memungkinkan dimunculkannya motif batik yang khas.

$\begin{array}{ccc}\text { Yang kedua, } & \text { teknik membatik } \\ \text { menggunakan teknik canting memang }\end{array}$ membutuhkan praktik dan pembiasaan praktik yang lama sehingga disarankan agar proses pelatihan membatik ini terus ditingkatkan oleh peserta di rumah masing-masing, agar pemakaian canting dan teknik pewarnaan batik bisa dikuasai. Saran berikutnya agar dibentuk sentra-sentra khusus untuk memasarkan produksi batik yang dihasilkan mitra, baik di tingkat kelurahan atau kecamatan dan kampus UMN bertindak sebagai penyelianya.Kegiatan ini juga mendapatkan banyak publikasi oleh media Ekonomi, Sosial, dan Budaya 1519 
massa seperti bisa dilihat pada link dibawah ini: https://www.baritorayapost.com/2019/08/berd ayakan-kelompok-perempuan-persit.html , dan https://nusantarapos.co.id/tmmd/37297/01/08 2019/di-desa-blukbuk-tangerang-istri-tnibekali-ibu-ibu-keterampilan-membatik-danhandy-craft/

\section{DAFTAR BACAAN}

http://sayaajarkan.com/infofeed/2017/10/24/5-teknik-membuat-batikyang-umum-dipakai-91403/

https://www.instagram.com/p/BOntZ1cHDdv/ https://www.instagram.com/p/BOns5RIne5J/ 